Ege Tıp Dergisi / Ege Journal of Medicine 2019; 58 (3): 239-245

\title{
Jinekolojik laparoskopi uygulanan hastaların serebral oksijenasyon takiplerinin retrospektif olarak incelenmesi
}

\author{
The retrospective evaluation of cerebral oxygenation monitorization in patients \\ undergoing gynecologic laparoscopy \\ Necmiye Ay ${ }^{1}$ Ayça Sultan Şahin ${ }^{1}$ Asuman Sargın ${ }^{2}$ Ziya Salihoğlu ${ }^{1}$ Z Abdurrahim Derbent ${ }^{2} \mathbb{D}$ \\ ${ }^{1}$ SBÜ Kanuni Sultan Süleyman Eğitim ve Araştırma Hastanesi, Anesteziyoloji ve Reanimasyon Kliniği, \\ İstanbul, Türkiye \\ ${ }^{2}$ Ege Üniversitesi Tıp Fakültesi, Anesteziyoloji ve Reanimasyon Anabilim Dalı, İzmir, Türkiye
}

Öz

Amaç: Laparaskopik cerrahide uygulanan Trendelenburg pozisyonu ve karbondioksit insüflasyonuyla oluşturulan pnömoperiton, serebral oksijen satürasyonu ( $\mathrm{rSO} 2$ ) ile pek çok sistemi etkilemektedir. Laparaskopik cerrahi sırasında serebral oksijen satürasyonunda oluşan değişiklikler, serebral oksimetre (NIRS) ile ölçülmektedir. NIRS kullanılarak, rSO2 düşüklüğü ve doku hipoksisi erkenden tespit edilebilmektedir. Bu çalışmada, jinekolojik laparoskopi olgularında uyguladığımız farklı pozitif end ekspiryum basıncı (PEEP) düzeylerinin serebral oksijenasyon ve hastaların hemodinamik verileri üzerine olan etkilerini retrospektif olarak araştırmayı planladık.

Gereç ve Yöntem: Jinekolojik laparoskopi uygulanmış, 69 hastanın dosyaları incelendi. 22 hastaya 8 PEEP, 23 hastaya 6 PEEP ve 24 hastaya 4 PEEP uygulanmış olduğu belirlendi. Bu hastaların oluşturduğu gruplara sırasıyla Grup 8, Grup 6 ve Grup 4 isimleri verildi. Non-invaziv ortalama kan basıncı (OKB), kalp hızı (KAH), oksijen satürasyonu (SpO2), end-tidal karbondioksit (ETCO2) ve rSO2 verilerini kaydedildi.

Bulgular: Hasta Trendelenburg pozisyonuna alındıktan ve intraperitoneal insuflasyon uygulandıktan sonraki KAH ve OKB'nin tüm gruplarda belirgin olarak azaldığı görüldü. Üç grupta da entübasyon sonrası ETCO2 değerine göre, sonrasında meydana gelen tüm ölçümler istatistiksel olarak anlamlı artmış $(p<0.05)$, SpO2 ve rSO2 değerlerinde meydana gelen değişimler ise istatistiksel olarak anlamlı olmamıştır. Tüm gruplardaki ETCO2 ile rSO2 arasında pozitif yönde anlamlı korelasyon vardı.

Sonuç: Trendelenburg pozisyonundaki laparoskopik cerrahilerde; 8 PEEP, 6 PEEP ve 4 PEEP uygulanmasının serebral oksijenasyonu etkilemediğini, $\mathrm{CO}_{2}$ insüflasyonuyla pnömoperiton oluşturulmasıyla meydana gelen ETCO2 artışın rSO2 değerlerini etkilediğini düşünmekteyiz.

Anahtar Sözcükler: Jinekolojik laparoskopi, pnömoperiton, Trendelenburg pozisyonu.

\begin{abstract}
Aim: Several systems and cerebral oxygen saturation are affected by Trendelenburg position and pneumoperitoneum created by carbon dioxide insufflation. Alterations in cerebral oxygen saturation (rSO2) during laparoscopic surgery and PEEP administration are measured by cerebral oximetry (NIRS). By using NIRS, depression in rSO2 tissue hypoxia and can be detected earlier, as soon as is affected. In this study, we aimed to investigate retrospectively the effects of different PEEP levels on cerebral oxygenation and hemodynamic effects of patients undergoing gynecologic laparoscopy.

Materials and Methods: The files of 69 patients undergoing gynecologic laparoscopy were analyzed. Eight 8 PEEPs in 22 patients, 6 PEEPs in 23 patients and 4 PEEPs in 24 patients had been administrated. The groups were named as Group 8, Group 6 and Group 4. Non-invasive arterial blood pressure $(A B P)$, heart rate $(H R)$, oxygen saturation, end-tidal carbon dioxide (ETCO2) and rSO2 were recorded in all patients.
\end{abstract}

Yazışma Adresi: Necmiye Ay

SBÜ Kanuni Sultan Süleyman Eğitim ve Araştırma Hastanesi,

Anesteziyoloji ve Reanimasyon Kliniği, İstanbul, Türkiye

E-mail: hisarneco@hotmail.com

Makalenin Geliş Tarihi: 18.05.2018

Kabul Tarihi: 09.07.2018 
Results: After the patient was put into Trendelenburg position and after intraperitoneal insufflations were given, $A B P$ and HR were significantly reduced in all groups. After intubation, in all groups ETCO2 was increased significantly, but the changes in $\mathrm{SpO} 2$ and rSO2 were not statistically significant. There was a significant positive correlation between ETCO2 and rSO2 in all groups $(p<0.05)$.

Conclusion: We think that during laparoscopic surgery in Trendelenburg position, administration of 8 PEEPs, 6 PEEPs and 4 PEEPs in did not affect cerebral oxygenation, ETCO2 increase due to CO2 insufflation and occurrence of pneumoperitoneum can affect the rSO2 values.

Keywords: Gynecologic laparoscopy, pneumoperitoneum, Trendelenburg position.

\section{Giriş}

Laparoskopik girişimlerde, Trendelenburg pozisyonu uygulanması ve $\mathrm{CO} 2$ insüflasyonu ile yapay pnömoperiton oluşturulması gerekmektedir. Pnömoperitonun etkisiyle atelektazi gelişerek oksijenasyon etkilenebileceğinden, hastalara intraoperatif olarak profilaktik pozitif end ekspiryum basıncı (PEEP) uygulanması önerilmektedir. Biz de rutin klinik uygulamamızda, Trendelenburgda ve CO2 insuflasyonu eşliğinde yapılan jinekolojik laparoskopi olgularında; hastaların oksijenasyonuna ve akciğer basınçlarına göre belirlediğimiz farklı PEEP düzeylerini intraoperatif olarak kullanmaktayız. Serebral oksijenasyonun etkilendiği durumları belirlemede standart monitörizasyon yeterli olmayabileceği için, son zamanlarda rSO2 ölçümüne yarayan serebral oksimetre (NIRS) gibi monitörler kullanıma girmiştir. NIRS sayesinde doku hipoksisi oluşmadan, serebral oksijenasyonun kötü yönde etkilenmeye başladığı erkenden saptanabilmektedir (1,9). Literatürde, Trendelenburg ve pnömoperiton uygulanan jinekolojik laparoskopi ameliyatlarında NIRS kullanılan az sayıda çalışmanın mevcut olduğu görülmektedir. Ancak, son yayınlarda robotik cerrahi, kardiyak cerrahi, travma cerrahisi, jinekolojik cerrahi ve laparoskopik cerrahi gibi farklı alanlarda da kullanıldığı göze çarpmaktadır (2). Kliniğimizde özellikle Trendelenburg pozisyonunda yapılan jinekolojik laparoskopik cerrahi olgularında hasta güvenliğini arttırmak, operasyon sırasında gelişebilecek komplikasyonları erkenden belirlemek ve önlem alabilmek için non-invaziv yöntem olan NIRS monitörizasyonu yapılmaktadır.

Çalışmadaki öncelikli amaç, Trendelenburg pozisyonu ve $\mathrm{CO} 2$ insuflasyonu uygulanmış hastalardaki farklı düzeylerde PEEP kullanımının serebral oksijenasyonu etkileyip etkilemediğini ortaya koymak olup, ikinci amaç ise hemodinamik etkilenme olup olmadığını belirlemektir.

\section{Gereç ve Yöntem}

$\mathrm{Bu}$ araştırma, Bakırköy Sadi Konuk Eğitim ve Araştırma Hastanesi Etik Kurul onayı (12.02.2018/2018-03-01) alındıktan sonra, Sağlık Bilimleri Üniversitesi Kanuni Sultan Süleyman Eğitim ve Araştırma Hastanesi Anesteziyoloji ve Reanimasyon Kliniği'nde koruyucu amaçla PEEP uygulanmış hastalarda, dosya verileri taranarak retrospektif olarak yapıldı. Genel anestezi ile jinekolojik laparoskopi uygulanmış, ASAI-II risk grubunda, 69 hastanın dosyaları incelendiğinde; 22 hastaya 8 PEEP, 23 hastaya 6 PEEP ve 24 hastaya 4 PEEP uygulanmış olduğu belirlendi. $\mathrm{Bu}$ hastaların oluşturduğu gruplara sırasıyla Grup 8, Grup 6 ve Grup 4 isimleri verildi.

Kliniğimizde, laparoskopik cerrahi yapılan ameliyathane odasında, peroperatif rutin monitörizasyonun (KAH, SpO2, ETCO2, noninvaziv kan basıncI) yanında NIRS (INVOS TM 5100C Cerebral/Somatic Oximeter, USA) cihazı ile non-invaziv olarak hastanın alnına yapıştııılan prob aracılığıyla serebral oksijenasyon monitörizasyonu (rSO2) yapılmakta ve tüm monitörizasyonlardan elde edilen veriler 5'er dakika aralıklar ile anestezi takip formuna kaydedilmektedir. Jinekolojik laparoskopide, kliniğimizde intraoperatif olarak sIVı yönetiminde 4-2-1 kuralına göre tüm hastalara standart uygulama yapılmaktadır. Tüm hastalara standart anestezi indüksiyonunda midazolam, propofol, fentanil ve roküronyum; anestezi idamesinde ise oksijen-hava karışımı içinde desfluran inhalasyon anestezisi ve remifentanil infüzyonu kullanılmaktadır.

Çalışmada; anestezi takip formuna kaydedilen $\mathrm{OKB}, \quad \mathrm{KAH}, \quad \mathrm{SpO} 2, \quad \mathrm{ETCO} 2$ gibi rutin monitörizasyon verilerinin yanı sıra hastalardan elde edilmiş olan NIRS verileri tarandı. Gruplara göre anestezi indüksiyonundan önce, entübasyon 
sonrası, insüflasyon sonrası abdominal basınç arttırilıp Trendelenburg pozisyonuna (AP-T) alındıktan sonra, AP-T'nin 5.dk, 10.dk, 15.dk, 20.dk, 25.dk verileri kaydedildi. Hastanın AP-T sonlanıp supin pozisyona alındıktan sonraki verileri ile cerrahi işlem bittiğinde ve anestezi sonlandığındaki verileri kaydedildi. Ayrıca her bir hastanın verilerinin kaydedildiği forma yaş, boy, kilo ve ASA değerleri yazıldı. Çalışmaya 18 yaş altı hastaların verileri ve eksik doldurulan dosyalar dahil edilmedi.

Çalışmada elde edilen verilerin istatistiksel analizinde SPSS 15.0 programı kullanıldı. Frekans, yüzde, ortalama, standart sapma gibi tanımlayıcı istatistiksel metotların yanı sıra, normal dağılımın incelenmesi için Kolmogorov-Smirnov dağılım testi, niteliksel verilerin karşılaştırılmasında Pearson KiKare testi, parametrelerin gruplar arası karşılaştırmalarında One Way ANOVA testi kullanıldı. Grup içi karşılaştırmalarda Repeated Measures ANOVA uygulandı. Sonuçlar \%95 güven aralığında, anlamlılık $p<0.05$ düzeyinde değerlendirildi.

\section{Bulgular}

Dosyaları taranan 69 hastanın demografik verileri Tablo-1'de sunulmuştur. Grup 8'de ASA-I 6 hasta (\%27.3), ASA-II 16 hasta (\%72.7), Grup 6'da ASA-I 4 hasta (\%17.4), ASA-II 19 hasta (\%82.6), Grup 4'de ASA-I 7 hasta (\%29.2), ASA-II 17 hasta (\%70.8) olarak bulundu. Grupların demografik özellikleri ve ASA risk grupları açısından gruplar arasında herhangi bir istatistiksel anlamlı fark gözlenmemiştir $(p>0.05)$ (Tablo-1).

Tablo-1. Gruplara Göre Yaş, Boy, Kilo Ortalamaları.

\begin{tabular}{lcccc}
\hline & Grup 8 & Grup 6 & Grup 4 & \\
& Ortalama \pm & Ortalama \pm & Ortalama & \\
& SS & SS & SS & $p$ \\
\hline \multirow{2}{*}{ Yas } & 40.773 & $46.348 \pm$ & $44.583 \pm$ & 0.186 \\
& \pm 9.401 & 13.340 & 7.192 & \\
Kilo (kg) & 72.591 & $77.652 \pm$ & $72.625 \pm$ & 0.329 \\
& \pm 12.682 & 13.459 & 13.233 & \\
Boy (cm) & $158.864 \pm$ & $159.783 \pm$ & $160.458 \pm$ & 0.678 \\
& 5.743 & 6.494 & 6.086 & \\
\hline
\end{tabular}

SS: Standart sapma, p>0.05 istatistiksel olarak anlamlı değil.
Gruplar arası OKB değerleri karşılaştırıldığında istatistiksel olarak anlamlı fark bulunmamıştır $(p>0.05)$. Ancak grup içindeki OKB değişimleri başlangıç düzeyleri ile karşılaştııılığında, üç grupta da anestezi öncesi OKB değerine göre, entübasyon sonrası düşüş ve sonrasında anestezi bitimine kadar olan dönemdeki azalma istatistiksel olarak anlamlıydı $(p<0.05)$ (Şekil-1).

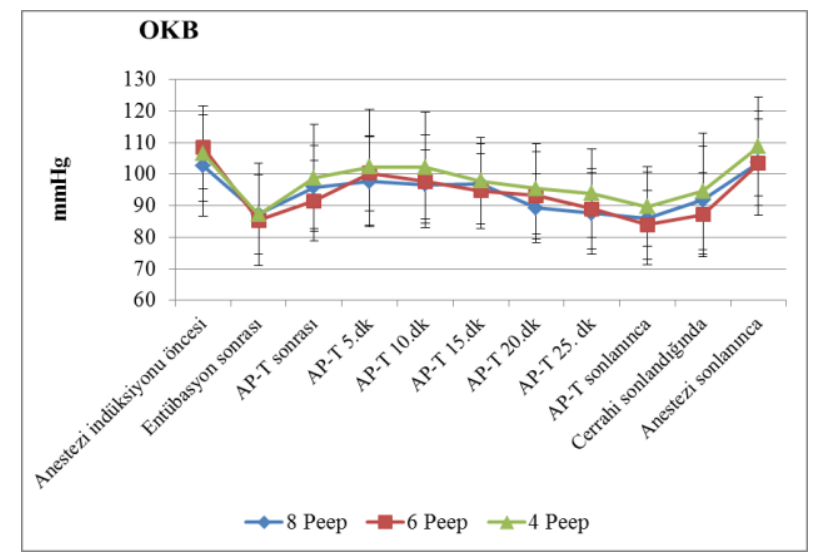

Şekil-1. OKB bulguları.

AP-T: Abdominal basınç sonrası Trendelenburg pozisyonu OKB: Ortama kan basıncı $(\mathrm{mmHg})$

Gruplar arası KAH karşılaştırıldığında istatistiksel olarak anlamlı fark bulunmamıştır $(p>0.05)$. Bununla birlikte Grup 8, Grup 6 ve Grup 4'te grup içinde anestezi indüksiyonu öncesi ve entübasyon sonrası KAH değerine göre; sonrasında meydana gelen $\mathrm{KAH}$ değişimlerinin istatistiksel olarak anlamlı olarak azalmış olduğu görülmüştür $(p<0.05)$ (Şekil-2).

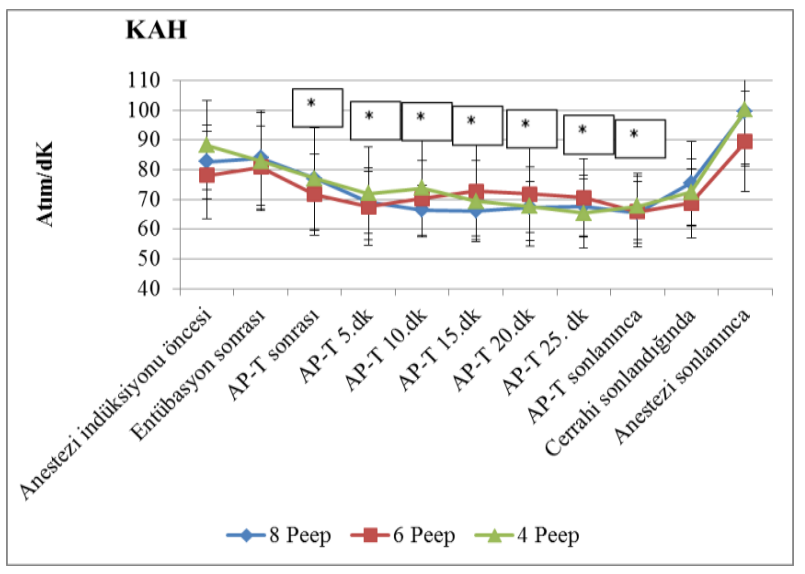

Şekil-2. KAH bulguları.

$\mathrm{KAH}:$ Kalp atım hızı (atım/dk) 
Gruplar arası ETCO2 ölçümleri açısından anlamlı fark bulunmamıştır ( $p>0.05)$ (Şekil-3). Üç grupta da entübasyon sonrası ETCO2 değerine göre, sonrasında meydana gelen değişimler istatistiksel olarak anlamlıdır $(p<0.05)$. Üç grupta da ölçülen ETCO2 değerleri entübasyon sonrasına göre; AP-T 5.dk, 10.dk, 15.dk, 20.dk, 25.dk'daki ve AP-T sonlandırıldığındaki değerler anlamlı derecede artmış olarak bulunmuştur $(p<0.05)$ (Şekil-3).

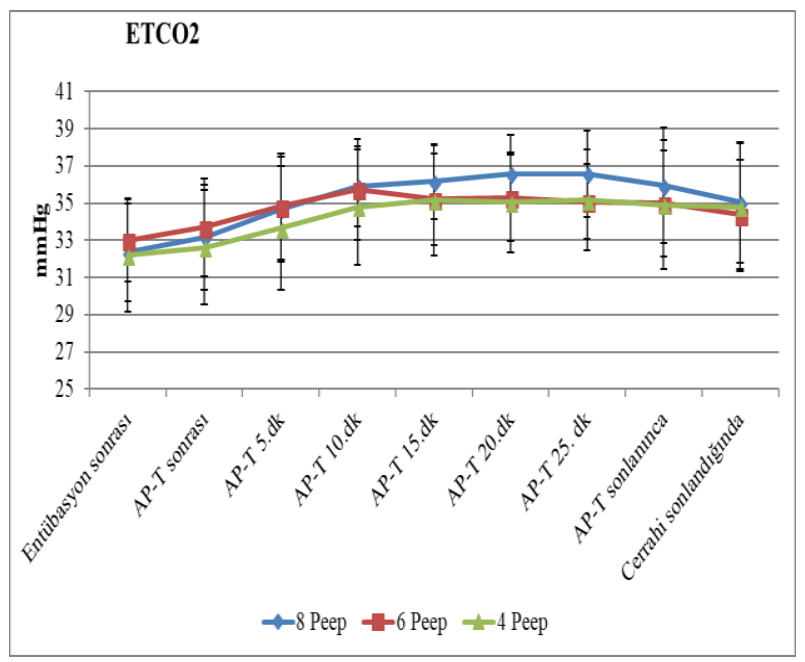

Şekil-3. ETCO2 bulguları.

ETCO2: End-tidal karbondioksit ( $\mathrm{mmHg}$ )

Gruplar arası SpO2'i değerleri karşılaştıııldığında; üç grupta da $\mathrm{SpO} 2$ değerlerinde meydana gelen değişimler istatistiksel olarak anlamlı değildir $(p>0.05)$ (Şekil-4).

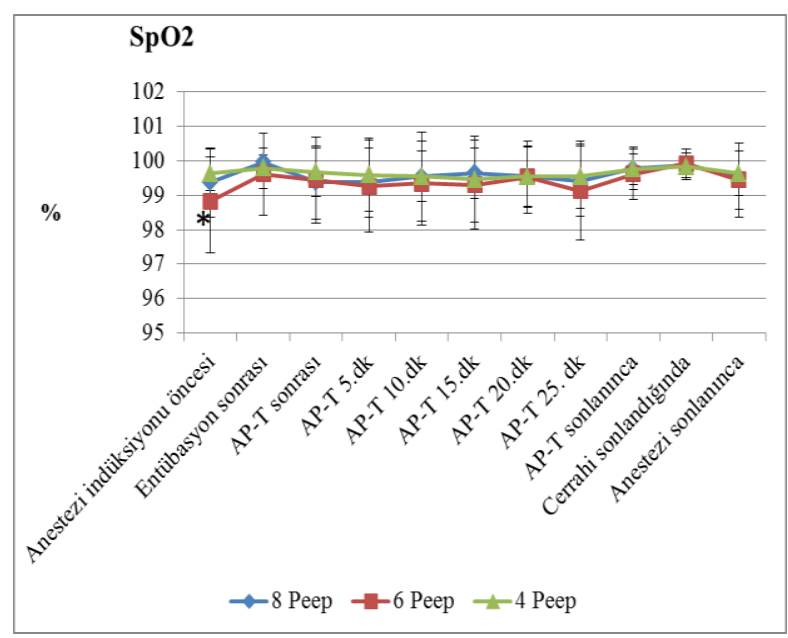

Şekil-4. SpO2 bulguları.

SpO2: Oksijen satürasyonu (\%)
Üç grupta da rSO2 değerlerinde meydana gelen değişimler istatistiksel olarak anlamlı değildir $(p>0.05)$. Tüm gruplarda OKB, KAH ve SPO2 ile rSO2 arasında anlamlı ilişki yoktur, ETCO2 ile rSO2 arasında pozitif anlamlı korelasyon vardır (Tablo-2, Şekil-5).

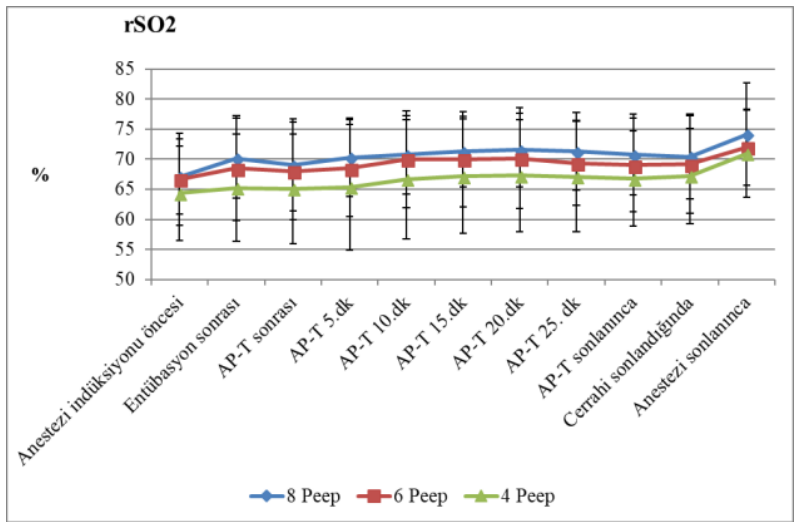

Şekil-5. rSO2 Bulguları

rSO2: Serebral doku oksijen satürasyonu (\%)

Tablo-2. rSO2 ile Diğer Vital Bulguların İlişkisi.

\begin{tabular}{cccccccc}
\hline & \multicolumn{4}{c}{ rSO2 } \\
& \multicolumn{2}{c}{8 PEEP } & \multicolumn{2}{c}{6 PEEP } & \multicolumn{2}{c}{4 PEEP } \\
& $\mathbf{r}$ & $\mathbf{p}$ & $\mathbf{r}$ & $\mathbf{p}$ & $\mathbf{r}$ & $\mathbf{p}$ \\
\hline \multirow{2}{*}{ OAB } & - & 0.936 & 0.114 & 0.739 & - & 0.894 \\
& 0.027 & & & & 0.045 & \\
KAH & - & 0.354 & 0.146 & 0.669 & - & 0.326 \\
& 0.310 & & & & 0.327 & 0.326 \\
ETCO2 & 0.975 & $\mathbf{0 . 0 0 0}$ & 0.895 & $\mathbf{0 . 0 0 1}$ & 0.765 & $\mathbf{0 . 0 1 6}$ \\
SPO2 & 0.227 & 0.501 & 0.162 & 0.633 & - & 0.230 & 0.496 \\
\hline
\end{tabular}

r: Korelasyon katsayısı

\section{Tartışma}

Laparoskopik jinekolojik girişimlerde, oksijenasyonu iyileştirmek ve perioperatif atelektazi gelişimini önlemek amacıyla, kliniğimizde rutin olarak hastaların gereksinimine göre farklı düzeylerde PEEP uygulanmaktadır. Laparoskopik cerrahide PEEP titrasyonu için konvansiyonel olarak hastanın oksijenasyonu, vücut kitle indeksi, vücut yapısı, uygulanan pozisyon, akciğer basınçları, akciğer kompliyansı ve basınç-volüm eğrisindeki 
alt infleksiyon noktasına göre belirlenmesinin yanı sıra günümüzde özofagial basınç ölçümü ve torasik impedans tomografi kullanılmasına yönelik çalışmalar vardır (3). Biz kliniğimizde laparoskopi sırasında PEEP titrasyonu amacıyla rutin olarak akciğer volümleri, basınçları ve hastanın oksijenasyonunu dikkate almaktayız.

Çalışmada, farklı düzeylerde PEEP uygulanmasının yol açtığı ortalama OKB değişiminin, gruplar arasında anlamlı bir farka yol açmadığı dosya kayıtlarında saptandı. Ancak tüm gruplarda başlangıç değerine göre, sonrasındaki ölçüm zamanlarında OKB'de anlamlı azalma saptanmıştır. Kan basıncındaki bu değişimlere pozitif basınçlı ventilasyon ve PEEP uygulamasının yol açı̆̆ı düşünülmektedir. PEEP ve pozitif basınçlı ventilasyonun temel olarak intratorasik basıncı arttırdığı, venöz geri dönüşü azalttığı, sol ventrikül fonksiyonuna olumsuz etki yaptığı ve özellikle bu etkinin kardiyak rezervi kısıtlı hastalarda daha belirgin olduğu saptanmıştır (4). Çalışmada grup içi ortalama arter basıncında anlamlı bir azalma meydana gelmiş, ancak bu azalma fizyolojik sınırların altına inmeyecek şekilde olmuş ve acil müdahale gerektirecek bir hipotansiyonun gelişmediği gözlenmiştir. Bunu bizim taradığımız dosyalardaki hastaların kardiyak rezervi kısıtlı olmayan ASAI-II hasta grubunda olmasına bağlayabiliriz.

Çalışmada, hasta kayıtları incelendiğinde kalp atım hızı (KAH) değişimleri açısından gruplar arasında anlamlı bir fark bulunmamıştır. Bununla birlikte, tüm gruplarda anestezi indüksiyonu öncesi ve entübasyon sonrası $\mathrm{KAH}$ değerine göre; sonrasında meydana gelen $\mathrm{KAH}$ değişimlerinin istatistiksel olarak anlamlı olarak azalmış olduğu görülmüştür. Çiçek ve ark. (5), $15 \mathrm{mmHg}$ dan daha düşük intraabdominal insuflasyon basıncı verilirken $10 \mathrm{cmH} 2 \mathrm{O}$ PEEP uygulandığında, gruplar arası değerlendirmede $\mathrm{KAH}$ ve kan basınçlarında istatistiksel ve klinik anlamda farklııı oluşmadığını görmüşlerdir. Bunun sonucunda da, $10 \mathrm{cmH} 2 \mathrm{O}$ PEEP uygulaması ile $15 \mathrm{mmHg}$ dan daha düşük insuflasyon basınçlarının, hemodinamik parametreleri olumsuz etkilemediğini ifade etmektedirler. Hastanemizdeki laparoskopik cerrahi operasyonlarda 15 mmHg'ı geçmeyen insuflasyon basınçları uygulanmaktadır.

Yong ve ark. (6) jinekolojik laparoskopik ve genel cerrahi laparoskopik girişimler sırasında meydana gelen kritik olayları 5 yıl süreyi içine alacak şekilde retrospektif olarak inceledikleri geniş çalışmada, pnömoperiton sonrası 14 kardiyak arrest meydana geldiğini, bunun 12'sinde öncesinde kalp atım hızında yavaşlama olduğunu saptamışlardır. Onlar da pnömoperiton sonrası meydana gelen bu kalp atım hızı azalmasının, periton gerilmesine bağlı olarak gelişen vagal refleks ile ilişkili olabileceğini belirtmişlerdir. Pnömoperiton azaltılması ve atropin sülfat ile bradikardinin geçtiğini belirtmişlerdir. Çalışmamızda da benzer şekilde pnömoperiton sonrası KAH azalması olmuş ancak ek bir müdahale gerektirecek bir hemodinamik bozulma gerçekleşmemiştir. KAH azalmasının Trendelenburg pozisyonu uygulanmasıyla birlikte pnömoperitonun peritonda gerilmeye yol açarak vagal refleksi ortaya çıkardığını ve KAH'da yavaşlamaya yol açtığını düşünebiliriz.

Trendelenburg pozisyonuyla diyafragmanın sefalada doğru yer değiştirdiği ve bunun sonucunun da fonksiyonel rezidüel kapasite (FRK)'de azalma ve ölü boşluk ventilasyonunda artma şeklinde olduğu ortaya konmuştur (7). FRK azalması ve alveol ölü boşluk artışının, ventilasyon-perfüzyon $(\mathrm{V} / \mathrm{Q})$ oranında dengesizliğe neden olduğu belirtilmektedir. Kim ve ark. (8) laparoskopik kolesistektomi uygulanan hastalarda, $5 \mathrm{cmH} 2 \mathrm{O}$ PEEP uygulamasının atelektazi oluşumunu azaltacağını ve oksijenasyonda düzelme sağladığını belirtmiş̧lerdir. Bizim çalışmamızda da hasta dosyaları incelendiğinde tüm laparoskopik cerrahi operasyonları geçiren hastalara PEEP uygulandığı tespit edildi ve üç grupta da SPO2 değerlerinde olumsuz etkilenme olmadığı görüldü.

Han ve ark. (9) laparoskopik histerektomilerde Trendelenburg pozisyonunda ve pnömoperiton sırasında kontrole göre rSO2'de anlamlı azalma gözlemişlerdir. Çalışmacılar, $30^{\circ}$ Trendelenburg pozisyonunun santral venöz basıncı arttırarak serebral venöz drenajı engellediği ve böylece intrakraniyal basıncı artırdığı ve rSO2'de anlamlı azalmaya yol açtığını belirtmiş̧lerdir (9). Mavrocordatos ve ark. (10) da, Trendelenburg uygulamasının intrakraniyal basınç ve rSO2'yi etkileyebileceğini belirmişlerdir.

Arteriyel kandaki karbondioksit serebral arteriyoler tonusun en güçlü düzenleyicisi olup, hiperkapni durumunda serebral arteriyollerin dilatasyonuyla serebral kan akışında ve hacminde artışa neden olur. Hipokapni vakalarında, nabız oksimetresi ile 
ölçülen oksijen satürasyonu normal olmasına rağmen serebral arteriyoler vazokonstriksiyona bağlı olarak serebral doku hipoksisi gelişebilir (11). Trendelenburg pozisyonu ve pnömoperitonun birlikte kullanılmasının sonucunda intrakraniyal hipertansiyonu arttırma olasılığı daha yüksektir (12). Park ve ark. (13), Trendelenburg pozisyonunda pnömoperiton uygulanan hastalarda NIRS kullanmışlar ve serebral oksijenasyonda hafif bir artış olduğunu görmüşlerdir. Bu çalışmada PaCO2'ni sabit tutmuşlar operasyonun sonunda artmış olan ETCO2'nin ve kalp hızının artmasının rSO2'deki artışın nedeni olduğu belirtmişlerdir. Bizim çalışmamızda, üç grupta da entübasyon sonrası ETCO2 değerine göre, daha sonra ölçülen ETCO2 değerleri istatistiksel olarak anlamlı artmış ve ETCO2 ile NIRS arasında anlamlı pozitif yönde korelasyon bulunmuştur. Biz de Park ve ark. (13) çalışmasına benzer şekilde rSO2 deki anlamlı artışın, ETCO2'nin artışının nedeni olduğunu düşünmekteyiz.

Teorik olarak, yüksek PEEP seviyeleri santral venöz basıncı arttırarak, kalp debisi ve kan basıncında azalma meydana getirir, bunun sonucunda da serebral perfüzyon basıncını (SPP) azaltıp intrakraniyal basıncını arttırabilir (14). Çalışmada her üç grup karşılaştırıldığında, NIRS değerlerinde meydana gelen değişimlerin istatistiksel olarak anlamlı olmadığını tespit ettik ve bu sonucun hastalara yüksek PEEP değerlerinin uygulanmamasına bağlı olduğunu düşünmekteyiz. Ayrıca hastalara yüksek olmayan PEEP kullanılmasının serebral hemodinamikler üzerine olumsuz etkisinin olmadığı kanısındayız. Çünkü kullandığımız PEEP değerinin, intrakraniyal basıncı aşan bir değer olmadığı ve maksimum $8 \mathrm{cmH} 2 \mathrm{O}$ olduğu için SPP'yi etkilemediği kanısındayız. Benzer bir şekilde yapılan bir çalışmada, Trendelenburg pozisyonu ve karbondioksit pnömoperiton sırasında $10 \mathrm{cmH} 2 \mathrm{O}$ PEEP uygulamasının, rS02 üzerinde hiçbir etkisinin olmadığı gösterilmiştir (15). Bu da bizim çalışma sonuçlarımızı desteklemektedir.

\section{Sonuç}

Çalışmamızda rSO2 bozukluğu saptanan hasta olmamıştır. Biz bunu serebral otoregülasyon veya perfüzyon bozukluğu için risk faktörü olan hasta grubunun olmamasına, sadece ASAI ve ASAll hasta grubunun bulunmasına bağlamaktayız. Bu nedenle de rutin rSO2 takibi kullanılmasını önermemekteyiz. Ancak serebral otoregülasyon veya perfüzyon bozukluğu için risk faktörü olan hasta grubunda kullanımı anlamlı olabilir. Bunlar bizim çalışmamızın limitasyonudur ve daha çok çalışma yapılmasına intiyaç vardır.

\section{Kaynaklar}

1. Pasch T, Zalunardo M. Intraoperatives Monitoring. Notwendiges, sinnvolles und überflüssiges. Anaesthetist 2000 ; 49 (1): 2-6.

2. Hoppenstein D, Zohar E, Ramaty E, Shabat S. The effects of general vs spinal anesthesia on frontal cerebral oxygen saturation in geriatric patients undergoing emergency surgical fixation of the neck of the femur. J Clin Anesth 2005; 17 (6): 431-8.

3. Carron E. Positive end-expiratory pressure in obese patients during general anaesthesia. The role of intraabdominal pressure. Br J Anaesth 2018; 120 (2): 409-10.

4. Luecke T, Pelosi P. Positive end-expiratory pressure and cardiac output. Critical Care 2005; 9 (6): 607-21.

5. Çiçek F, Ün C, Kılcı O ve ark. The effects of $10 \mathrm{cmH} 2 \mathrm{O}$ positive end-expiratory pressure on arterial oxygenation, respiratory mechanics and hemodynamic parameters in laparoscopic cholecystectomy operations. $\mathrm{J}$ Clin Exp Invest 2014; 5 (3): 397-402.

6. Yong J, Hibbert P, Runciman WB, Coventry BJ. Bradycardia as an early warning sign for cardiac arrest during routine laparoscopic surgery. Int J Qual Health Care 2015; 27 (6): 473-8.

7. Takahata $\mathrm{O}$, Kunisawa $\mathrm{T}$, Nagashima $\mathrm{M}$, et al. Effect of age on pulmonary gas exchange during laparoscopy in the Trendelenburg lithotomy position. Acta Anaesthesiol Scand 2007; 51 (6): 687-92.

8. Kim JY, Shin CS, Kim HS, et al. Positive end-expiratory pressure in pressure-controlled ventilation improves ventilatory and oxygenation parameters during laparoscopic cholecystectomy. Surg Endosc 2010; 24 (5): 1099-103. 
9. Han S, Moon H, Oh Y, Lee J. Cerebral oxygenation during gynecologic laparoscopic surgery. Anesthesiology 2003; 99: A277.

10. Mavrocordatos, P, Bissonnette, B, Ravussin, P. Effects of neck position and head elevation on intracranial pressure in anaesthetized neurosurgical patients: Preliminary results. J Neurosurg Anesthesiol 2000; 12 (1): 10-4.

11. Vegh $T$, Szatmari $S$, Juhasz $M$, et al. One-lung ventilation does not result in cerebral desaturation during application of lung protective strategy if normocapnia is maintained. Acta Physiol Hung 2013; 100 (2): 163-72.

12. Halverson A, Buchanan R, Jacobs $L$, et al. Evaluation of mechanism of increased intracranial pressure with insufflation. Surgical Endoscopy 1998; 12 (3): 266-9.

13. Park EY, Koo BN, Min KT, Nam SH. The effect of pneumoperitonium in the steep Trendelenburg position on cerebral oxygenation. Acta Anaesthesiol Scand 2009; 53 (7): 895-9.

14. Muench $\mathrm{E}$, Bauhuf $\mathrm{C}$, Roth $\mathrm{H}$, et al. Effects of positive end-expiratory pressure on regional cerebral blood flow, intracranial pressure, and brain tissue oxygenation. Crit Care Med 2005; 33 (10): 2367-72.

15. Jo YY, Lee JY, Lee MG, Kwak HJ. Effects of high positive end-expiratory pressure on haemodynamics and cerebral oxygenation during pneumoperitonium in the Trendelenburg position. Anaesthesia 2013; 68 (9): 938-43. 